\section{How green is my future?}

UN panel foresees big growth in renewable energy, but policies will dictate just how big. BY JEFF TOLLEFSON A SMALL SLICE

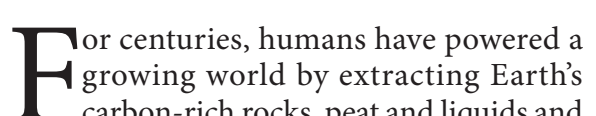
growing world by extracting Earth's
carbon-rich rocks, peat and liquids and burning them in ever greater amounts, but
that trend is beginning to change. A report from the Intergovernmental Panel on Climate Change (IPCC), released on 9 May at a briefing slow - shift towards specialized energy crops sunlight, wind and other sources of renewable power will mark the next four decades. In addition to surveying published work on renewable energy potential, production, detailed socioeconomic modelling acted 164 scenarios, both with and without policies intended to reduce greenhouse-gas emissions. The extent and type of development varies significantly depending on factors such as price and technological progress, and on government policies sions. "Renewables will have a great future even without climate policies, but that does not necessarily lead to an emissions reduction," says Ottmar Edenhofer, chairman of the IPCC's working group on mitigation. Renewable energy sources, excluding the make up roughly $7 \%$ of sloble sas wood, duction (see 'A small slice'), and the working group's Summary for Policymakers estimates that by 2050 , production could rise to between three and more than ten times its current level. No renewable technology is projected wind will be bu bione gy, solar phergy and 'The big be impe'). This shift towards renewable energy could reduce cumulative greenhousegas emissions by $220-560$ gigatonnes of car-
bon dioxide, from a baseline estimate of 1,530 gigatonnes.

In all scenarios, fossil fuel will continue to have an important role for decades to come. able energy will drive a gradual deployment of clean energy, but overhauling the global energy system represents a monumental task (see 'Planet renewable'). The IPCC says there are no technical barriers preventing large-scale the next few decades. And even in 2050 , none of the four main scenarios shows humatity tapping more than $2.5 \%$ of the accessible supply of renewable energy.. \begin{tabular}{l} 
energy \\
$2.0 \%$ \\
\hline
\end{tabular}
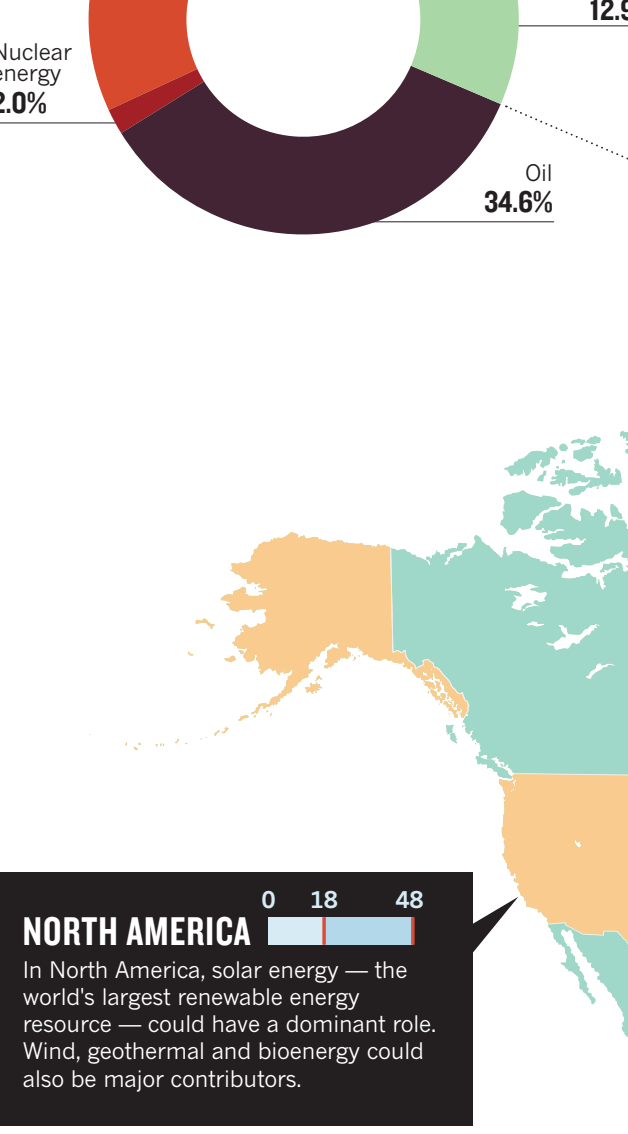
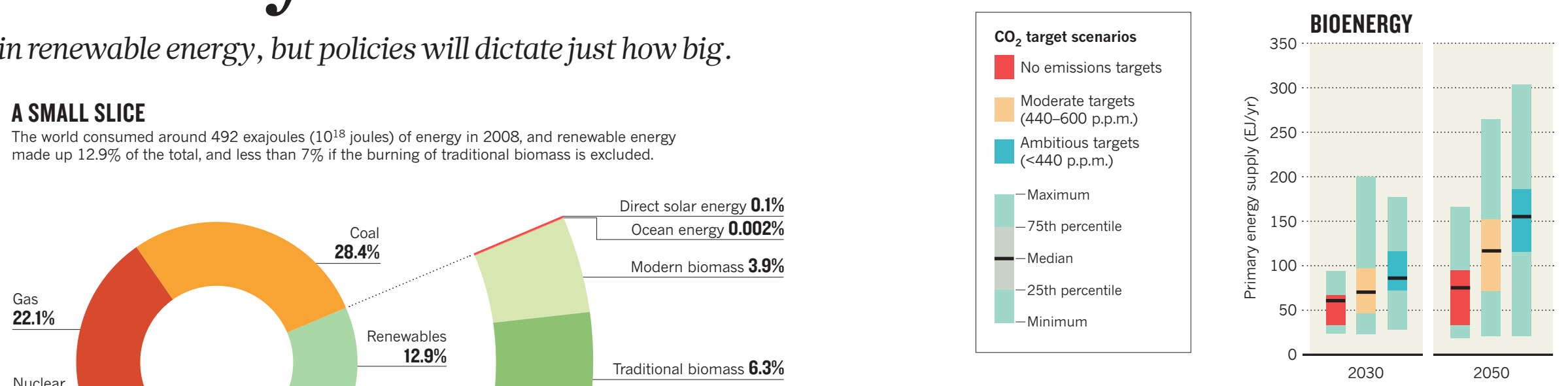

DIRECT SOLAR ENERGY

WIND ENERGY

THE BIG THREE

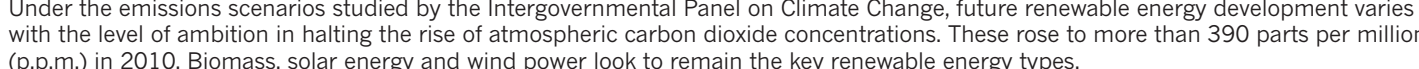

\begin{tabular}{|l|}
\hline $\mathrm{CO}_{2}$ target scenarios \\
No emissions targets \\
Moderate targets \\
(440-600 p.p.m.) \\
Ambitious targets \\
( 440 p.p.m.) \\
-Maximum \\
-75th percentile \\
- -Median \\
-25th percentile \\
- Minimum \\
\hline
\end{tabular}
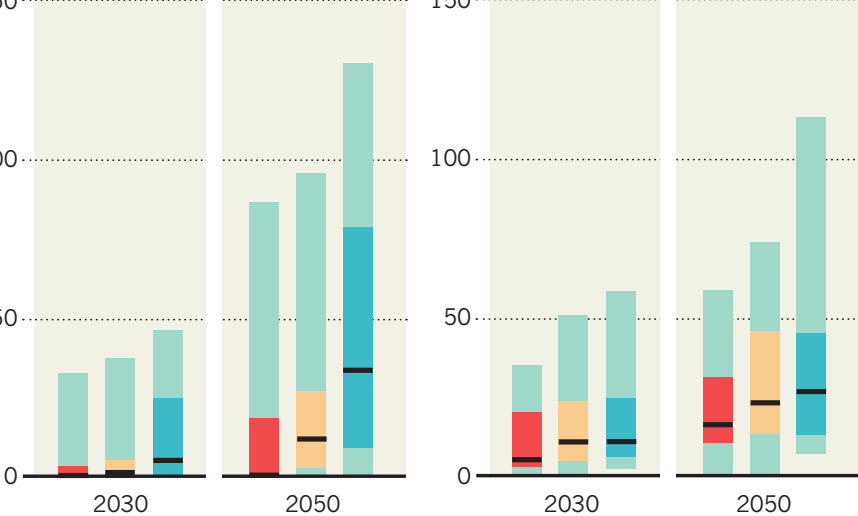

PLANET RENEWABLE

that by 2050 renewables could grow from 2008 levels of 32 exajoules per year to about $100-300$ EJ/yr globally. Renewable energy could
provide $15-77 \%$ of the global powers supply. The lowest and highest
projections in the four scenarios are estimated for selected regions.

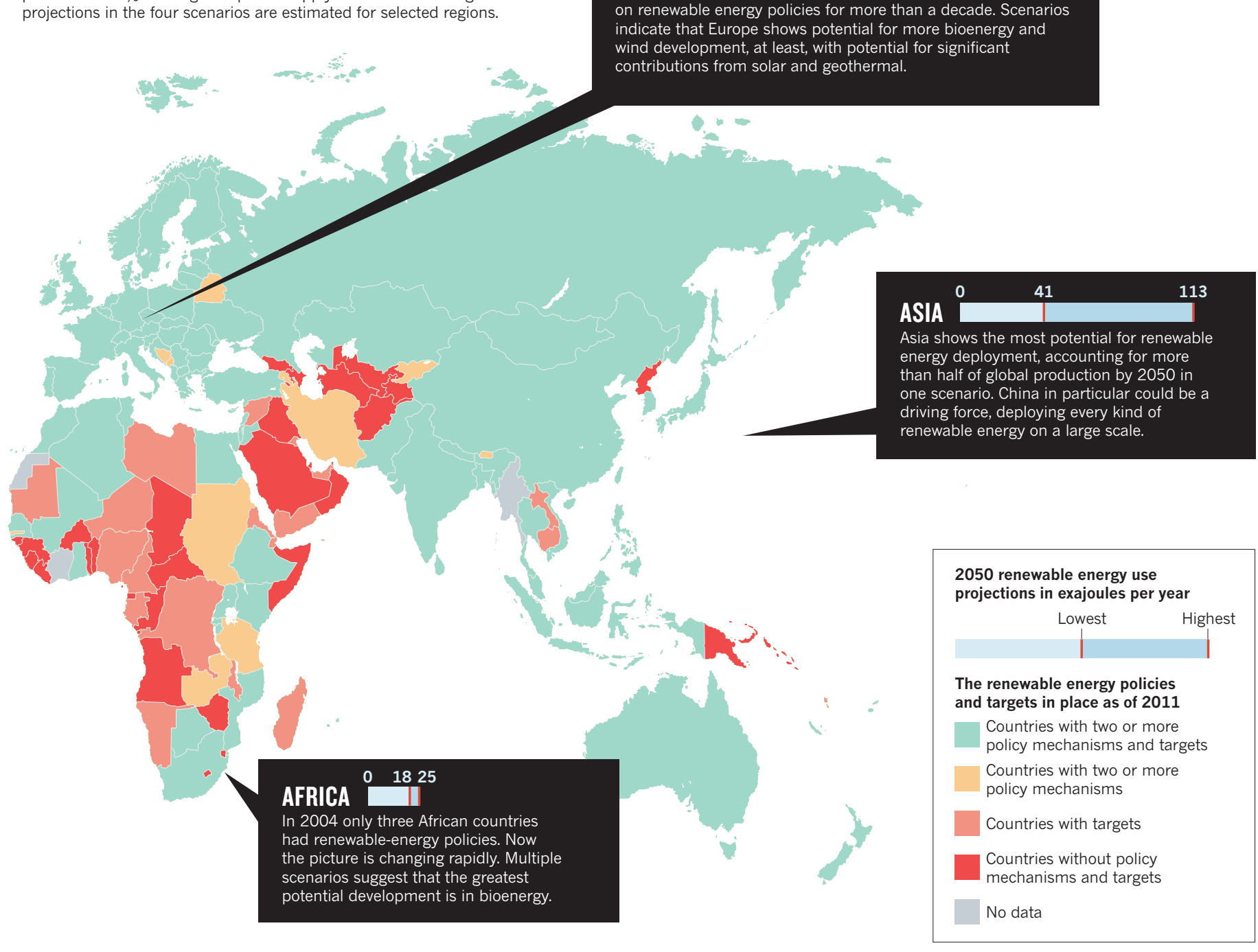

